\title{
Mutations in the WTX - gene are found in some high-grade microsatellite instable (MSI-H) colorectal cancers
}

\author{
Silvio K Scheel ${ }^{1}$, Marc Porzner ${ }^{2}$, Sabine Pfeiffer ${ }^{1}$, Steffen Ormanns ${ }^{1}$, Thomas Kirchner ${ }^{1}$, Andreas Jung ${ }^{1 *}$
}

\begin{abstract}
Background: Genetically, colorectal cancers (CRCs) can be subdivided into tumors with chromosomal instability (CIN) or microsatellite instability (MSI). In both types of CRCs genes that are involved in the degradation of $\beta$ CATENIN are frequently mutated. Whereas in CIN CRCS APC (Adenomatous Polyposis Coli) is affected in most cases, high grade MSI (MSI-H) CRCs frequently display mutations in various genes, like the APC-, AXIN2- or CTNNBI ( $\beta$ CATENIN) gene itself. Recently in Wilms tumors, WTX (Wilms tumor gene on the X-chromosome) was discovered as another gene involved in the destruction of $\beta$-CATENIN. As the WTX-gene harbors a short $\mathrm{T}_{6}$-microsatellite in its $\mathrm{N}$ terminal coding region, we hypothesized that frameshift-mutations might occur in MSI-H CRCs in the WTX gene, thus additionally contributing to the stabilization of $\beta$-CATENIN in human CRCs.
\end{abstract}

Methods: DNA was extracted from 632 formalin-fixed, paraffin-embedded metastatic CRCs (UICCIV) and analyzed for MSI-H by investigating the stability of the highly sensitive microsatellite markers BAT25 and BAT26 applying fluorescence capillary electrophoresis (FCE). Then, in the MSI-H cases, well described mutational hot spot regions from the APC-, AXIN2- and CTNNB/ genes were analyzed for genomic alterations by didesoxy-sequencing while the WTX $T_{6}$-microsatellite was analyzed by fragment analysis. Additionally, the PCR products of $T_{5}$-repeats were subcloned and mutations were validated using didesoxy-sequencing. Furthermore, the KRAS and the BRAF protooncogenes were analyzed for the most common activating mutations applying pyro-sequencing. mRNA expression of WTX from MSI-H and MSS cases and a panel of colorectal cancer cell lines was investigated using reverse transcription (RT-) PCR and FCE.

Results: In our cohort of 632 metastatic CRCs (UICCIV) we identified 41 MSI-H cases (6.5\%). Two of the 41 MSI-H cases (4.8\%) displayed a frameshift mutation in the $T_{6}$-repeat resulting in a $T_{5}$ sequence. Only one case, a male patient, expressed the mutated WTX gene while being wild type for all other investigated genes.

Conclusion: Mutations in the WTX-gene might compromise the function of the $\beta$-CATENIN destruction complex in only a small fraction of MSI-H CRCs thus contributing to the process of carcinogenesis.

\section{Background}

Genetically, colorectal cancers (CRCs) might be subdivided into two groups. One group is characterized by chromosomal instability (CIN) and follows the classical multistep carcinogenesis model where mutations result in the activation of proto-oncogenes (gain of function) or the inhibition of tumor suppressor genes (loss of function) by this driving the process of colorectal

\footnotetext{
* Correspondence: andreas.jung@Imu.de

${ }^{1}$ Pathologisches Institut der Ludwig-Maximilians-Universität München,

Thalkirchner Straße 36, 80337 Munich, Germany

Full list of author information is available at the end of the article
}

carcinogenesis [1]. The other group is characterized by high grade instability of microsatellites (MSI-H) and can be subdivided into sporadic and heritable forms and accounts for approximately $15 \%$ of all CRCs. The majority of sporadic MSI-H CRCs is characterized by loss of expression of the MLH1 (MUT-L homologue 1) gene, a component of the mismatch repair (MMR) system due to methylation of its promoter/exon 1 region. These MSI-H CRCs belong to the CIMP (CpG island methylator phenotype) and are highly associated with mutations in the BRAF proto-oncogene (up to 75\%) [2]. In contrast, the heritable forms of MSI-H CRCs, known as
C Biomed Central 
hereditary non polyposis colorectal cancers (HNPCC), harbor mutations in genes of the MMR-system, like MLH1, MSH2 (MUT-S homologue 2), MSH6 or PMS2 (post mitotic segregation 2). Thus, in MSI-H tumors, the function of the MMR-system is lost [3]. This in turn leads to frameshift mutations in microsatellites, which might contribute to the malignant transformation of tumor cells when located in the coding sequences of tumor suppressor genes like the TGFBR2 (TGF- $\beta$ receptor type 2) [4]. This type of mutation and the associated occurrence of neoantigenic structures might explain why sporadic MSI-H CRCs have a better prognosis than microsatellite stable (MSS) CRCs [5].

Interestingly, the stabilization of $\beta$-CATENIN, which is the executor of the canonical WNT-signaling pathway, is affected in both, MSI-H and MSS CRCs. In the WT situation $\beta$-CATENIN is earmarked for degradation by a multi-protein complex assembled of at least APC, AXIN2, PP2A (pyro-phosphatase 2 A) and GSK3B (glycogen synthase kinase $3 \beta$ ). In MSS CRCs, the stabilization of $\beta$-CATENIN is mostly achieved by mutations in the tumor suppressor gene $A P C$, which is considered to be the gatekeeper of colorectal carcinogenesis [1]. In contrast in MSI-H CRCs, the stabilization of $\beta$-CATENIN seems to be a later event and is achieved by loss of function in $A P C$ [6-8] in only $14-56 \%$, while in $24 \%$ mutations are found in the AXIN2- [8] or in up to $43 \%$ in the CTNNBI-gene itself, depending on if investigating sporadic or heritable cases of CRC [6,8-11]. Expectedly in MSI-H CRCs, the loss of function mutations in the $A P C$ and $A X I N 2$-tumor suppressor genes partly results from frameshift mutations, thus highlighting the causative role of the MMR system in MSI-H CRCs.

Recently in Wilms tumors, WTX (Wilms Tumor gene on the $\mathrm{X}$-Chromosome) was discovered as another component of the $\beta$-CATENIN degradation complex where it directly interacts with $\beta$-CATENIN and APC $[12,13]$. Moreover, Wilms tumors are often characterized by a deregulated WNT-signaling pathway which can be attributed to mutations in the WTX-gene in 7 to $30 \%$ of all cases $[14,15]$. Due to its location on the X-chromosome, WTX resembles a one hit tumor suppressor which has therefore a higher penetrance in men than in women.

Because of its role in the degradation of $\beta$-CATENIN and the presence of a short six basepair long T-repeat $\left(\mathrm{T}_{6}\right)$ in the $\mathrm{N}$-terminus encoding part of the WTX-gene, we hypothesized that WTX might also contribute to the stabilization of $\beta$-CATENIN in MSI-H CRCs. Therefore, we investigated if frameshift mutations are present in the $\mathrm{T}_{6}$-repeat of the WTX-gene in the MSI-H fraction of a collection of metastatic CRCs (UICCIV).

\section{Methods}

\section{Clinical samples}

632 cases of formalin fixed, paraffin-embedded (FFPE) tissue of metastatic CRCs (UICCIV) were selected for the investigation. The usage of these cases for scientific reasons was approved by the local ethics committee of the Medical Faculty of the Ludwig-Maximilians-Universität München.

\section{DNA and RNA isolation}

After removal of paraffin wax using graded xylene- and alcohol dilutions following routine protocols, tumor cells were manually dissected from the slides. Subsequently, DNA and RNA were extracted using QIAamp DNA Micro kits or RNeasy FFPE kits (Qiagen, Hilden, Germany), respectively following the instruction manuals.

\section{Cell lines, Cell culture and RNA isolation}

Cultivated colorectal tumor cell lines RKO, LoVo, SW480, Caco2, DLD-1, HCT15, HCT116, LS174T and HT29 were purchased from the ATCC (LGL Promochem $\mathrm{GmbH}$, Wesel, Germany) and maintained in DMEM (Biochrom, Berlin, Germany) containing 7.5\% (v/v) fetal bovine serum (Biochrom, Berlin, Gemany). RNA was isolated using RNeasy Mini kits (Qiagen, Hilden, Germany) according to the user's instructions.

\section{PCR, reverse transcription, RT-PCR, fluorescence capillary} electrophoresis (FCE), didesoxy- and pyro-sequencing

For the determination of MSI-H polymerase chain reactions (PCRs) specific for the monomorphic mononucleotide microsatellites BAT25 and BAT26 were done using $1 \mu \mathrm{l}$ DNA as the template in the presence of $1.5 \mathrm{mM}$ $\mathrm{MgCl}_{2}, 200 \mu \mathrm{M}$ dNTPs (Fermentas, St. Leon, Germany), $400 \mathrm{nM}$ of each of BAT25 or BAT26 specific primer pairs (Additional file 1, Table S1), respectively together with 1 U HotStarTaq Polymerase (Qiagen, Hilden, Germany) following the user's manual. Male DNA (Promega, Mannheim, Germany) was used as the template for positive- and water for negative controls. PCRs specific for the mutation hot spots of the $A P C$ - (exon 15) [7], AXIN2- (exon 8) [8] and CTNNBI- (exon 3) [16,17] genes as well as the $\mathrm{T}_{6}$-microsatellite of the $W T X$-gene were done using the same protocol together with genespecific primers (Additional file 1, Table S1). $1 \mu$ of the final PCR products was used for subsequent sequencing using BigDye Terminator v1.1 kits (Applied Biosystems, Darmstadt, Germany) together with appropriate primers (500 nM, Additional file 1, Table S1). Reactions were purified using DyeEx v2.0 kits (Qiagen, Hilden, Germany) following the handbook. $4 \mu \mathrm{l}$ purified 
Table 1 Overview of patient age, gender and mutations found in MSI-H CRCs

\begin{tabular}{|c|c|c|c|c|c|c|c|c|}
\hline Patient ID & Age & Gender & $W T X$ & $\begin{array}{l}A P C \\
\text { Exon } 15\end{array}$ & $\begin{array}{l}\text { AXIN2 } \\
\text { Exon } 8\end{array}$ & $\begin{array}{l}\text { CTNNB1 } \\
\text { Exon } 3\end{array}$ & $\begin{array}{l}\text { KRAS } \\
\text { Codon 12/13 }\end{array}$ & $\begin{array}{l}\text { BRAF } \\
\text { Codon } 600\end{array}$ \\
\hline 1 & 65 & $\mathrm{~m}$ & $T_{5}$ & WT & WT & WT & WT & WT \\
\hline 2 & n.a. & $f$ & $T_{5}$ & WT & WT & WT & WT & c.1799T>A \\
\hline 3 & 52 & $\mathrm{~m}$ & $\mathrm{~T}_{6}$ & WT & WT & WT & WT & WT \\
\hline 4 & 74 & $\mathrm{~m}$ & $T_{6}$ & WT & $\begin{array}{l}1 \text { bp del (G) } \\
\text { codon } 665\end{array}$ & WT & WT & n.a. \\
\hline 5 & 68 & f & $T_{6}$ & WT & WT & WT & c.35G $>A$ & WT \\
\hline 6 & 28 & $\mathrm{~m}$ & $T_{6}$ & $\begin{array}{l}2 \text { bp del (AG) } \\
\text { codon } 1462\end{array}$ & WT & WT & WT & WT \\
\hline 7 & 72 & $f$ & $\mathrm{~T}_{6}$ & WT & WT & WT & WT & c.1799T>A \\
\hline 8 & 65 & $f$ & $T_{6}$ & n.a. & n.a. & n.a. & WT & WT \\
\hline 9 & 63 & $f$ & $\mathrm{~T}_{6}$ & $\begin{array}{l}\text { c.2312A>G } \\
\text { p.E770G }\end{array}$ & WT & WT & WT & c.1799T>A \\
\hline 10 & n.a. & $\mathrm{m}$ & $T_{6}$ & $\begin{array}{l}\text { c.2393A>G } \\
\text { p.G797D }\end{array}$ & WT & WT & WT & c.1799T>A \\
\hline 11 & 77 & $f$ & $T_{6}$ & WT & WT & WT & WT & WT \\
\hline 12 & 65 & $f$ & $T_{6}$ & WT & WT & WT & WT & c.1799T>A \\
\hline 13 & 75 & $m$ & $T_{6}$ & $\begin{array}{l}1 \text { bp ins (A) } \\
\text { codon } 1554\end{array}$ & WT & WT & WT & c.1799T>A \\
\hline 14 & 69 & $f$ & $T_{6}$ & WT & $\begin{array}{l}\text { c.2062C>T (mut/mut) } \\
\text { p.P687L }\end{array}$ & $\begin{array}{l}\text { c.64G>A } \\
\text { p.V221 }\end{array}$ & WT & WT \\
\hline 15 & 72 & $f$ & $T_{6}$ & WT & WT & WT & WT & c.1799T>A \\
\hline 16 & 46 & $\mathrm{~m}$ & $T_{6}$ & WT & $\begin{array}{l}\text { c. } 2073 \mathrm{C}>\mathrm{T} \\
\text { p.691Q }>\text { STOP }\end{array}$ & WT & WT & WT \\
\hline 17 & 45 & $f$ & $\mathrm{~T}_{6}$ & $\begin{array}{l}1 \text { bp ins (A) } \\
\text { codon } 1554\end{array}$ & WT & WT & WT & c.1799T>A \\
\hline 18 & 42 & $\mathrm{~m}$ & $T_{6}$ & WT & WT & WT & WT & WT \\
\hline 19 & n.a. & $\mathrm{m}$ & $T_{6}$ & WT & WT & WT & WT & WT \\
\hline 20 & 76 & $m$ & $\mathrm{~T}_{6}$ & WT & WT & WT & WT & c.1799T>A \\
\hline 21 & 76 & $m$ & $\mathrm{~T}_{6}$ & WT & WT & WT & WT & WT \\
\hline 22 & 78 & $f$ & $\mathrm{~T}_{6}$ & WT & $\begin{array}{l}c .2037 C>T \\
\text { p.H679Y and } \\
\text { c.2071C>T } \\
\text { p.691Q }>\text { STOP }\end{array}$ & WT & WT & WT \\
\hline 23 & 56 & $f$ & $T_{6}$ & WT & WT & $\begin{array}{l}\text { c.134C>T } \\
\text { p.S45F }\end{array}$ & WT & c.1799T>A \\
\hline 24 & 33 & $\mathrm{~m}$ & $\mathrm{~T}_{6}$ & WT & WT & WT & WT & WT \\
\hline 25 & 73 & $f$ & $T_{6}$ & WT & WT & WT & WT & C.1799T>A \\
\hline 26 & 65 & $f$ & $\mathrm{~T}_{6}$ & WT & $\begin{array}{l}\text { c.2103T>C } \\
\text { p.S701P }\end{array}$ & WT & WT & c.1799T>A \\
\hline 27 & 77 & $f$ & $T_{6}$ & WT & WT & WT & WT & WT \\
\hline 28 & 69 & $\mathrm{~m}$ & $T_{6}$ & WT & WT & WT & WT & WT \\
\hline 29 & 43 & $m$ & $T_{6}$ & WT & WT & WT & WT & WT \\
\hline 30 & 64 & $f$ & $T_{6}$ & WT & WT & WT & WT & WT \\
\hline 31 & 43 & $m$ & $T_{6}$ & WT & WT & WT & WT & WT \\
\hline 32 & 43 & $m$ & $T_{6}$ & WT & WT & WT & WT & WT \\
\hline 33 & 54 & $m$ & $T_{6}$ & WT & WT & WT & WT & WT \\
\hline 34 & 66 & $f$ & $T_{6}$ & WT & $\begin{array}{l}\text { c.2062C>T } \\
\text { p.P687L }\end{array}$ & WT & WT & WT \\
\hline 35 & 40 & $f$ & $T_{6}$ & WT & WT & WT & WT & WT \\
\hline 36 & 60 & $m$ & $\mathrm{~T}_{6}$ & n.a. & n.a. & n.a. & n.a. & WT \\
\hline
\end{tabular}


Table 1 Overview of patient age, gender and mutations found in MSI-H CRCs (Continued)

\begin{tabular}{|c|c|c|c|c|c|c|c|c|}
\hline 37 & 63 & $f$ & $\mathrm{~T}_{6}$ & WT & WT & WT & c. $35 \mathrm{G}>\mathrm{A}$ & WT \\
\hline 38 & 73 & $\mathrm{~m}$ & $T_{6}$ & WT & WT & WT & WT & WT \\
\hline 39 & 72 & f & $T_{6}$ & WT & $\begin{array}{l}\text { c. } 2077 A>G \\
\text { p.H692R }\end{array}$ & WT & WT & WT \\
\hline 40 & 65 & f & $T_{6}$ & n.a. & n.a. & n.a. & WT & n.a. \\
\hline 41 & 52 & $\mathrm{~m}$ & $T_{6}$ & $\begin{array}{l}\text { c.2626C }>T \\
\text { p.876R }>\text { STOP } \\
\text { and } \\
2 \text { bp del (AG) } \\
\text { codon } 1462\end{array}$ & WT & WT & WT & WT \\
\hline
\end{tabular}

PCR product were mixed together with $16 \mu$ l highlydeionized formamide (HiDi, Applied Biosystems, Darmstadt, Germany), heated for 2 minutes at $90^{\circ} \mathrm{C}$, cooled down immediately on ice and loaded onto the genetic analyzer 3130 (Applied Biosystems, Darmstadt, Germany). Results were finally analyzed with the help of the Sequencing Analysis v5.2- (Applied Biosystems, Darmstadt, Germany) and Geneious-software (Biomatters Ltd., Australia).

For sequencing the fragments generated from the WTX-gene, PCRs were repeated using the same but unlabelled primers (Additional file 1, Table S1) as for the screening for mutations. Resulting PCR products were subcloned using the CloneJet PCR cloning kit (Fermentas, St. Leon, Germany) according to the user's manual and finally sequenced as described above.

For reverse transcription, $1 \mu \mathrm{g}$ of RNA was converted into cDNA using QuantiTect Reverse Transcription kits (Qiagen, Hilden, Germany) in the presence $(+)$ or absence (-) of reverse transcriptase (RT) following the user's manual. For subsequent WTX specific PCRs $1 \mu \mathrm{l}$ of a fiftyfold diluted cDNA solution was used as the template but else applying the same conditions as described above. RT-PCR specific for the housekeeping gene ACTB ( $\beta$-ACTIN, [GenBank: NM_001101]) served as a control using $\beta$-ACTIN specific primers (Additional file 1, Table S1). Products from RT-PCR were separated on $2 \% 0.5 \times$ TBE agarose gels containing $100 \mathrm{ng} / \mathrm{ml}$ ethidium bromide and visualized under UV-light.

For the analysis microsatellite-stability PCR products were separated by capillary electrophoresis using an ABI 3130 sequencing analyzer by mixing $1 \mu \mathrm{l}$ of the PCR products with $18.5 \mu$ l highly-deionized formamide (HiDi) and $0.5 \mu \mathrm{l}$ of the GeneScan-500 LIZ size standard (both Applied Biosystems, Darmstadt, Germany), heated for 2 minutes at $90^{\circ} \mathrm{C}$, cooled down immediately on ice, and subsequently loaded onto the genetic analyzer 3130 . Finally, results were analyzed with the help of the GeneMapper v4.0 software (Applied Biosystems, Darmstadt, Germany).

Mutations in codons 12 and 13 of the KRAS- and codon 600 of the BRAF-gene were done as described
$[18,19]$ using Pyromark-Gold reagents (Qiagen, Hilden Germany) together with the appropriate primers (Additional file 1, Table S1) following the user's instructions.

\section{Results}

First of all, MSI-H CRCs were identified from our collection of 632 cases of metastatic CRCs (UICCIV) by investigating the stability of the highly sensitive and specific monomorphic mononucleotide markers BAT25 and $B A T 26[20,21]$ using PCR based fluorescence capillary electrophoresis (FCE). We detected instability of both microsatellite markers in 41 out of 632 cases (6.5\%) compared to control DNA (Figure 1A, tumor ID \#1, \#2 (both MSI-H), \#42 (MSS) and Table 1). These 41 cases were taken for all further investigations as we aimed to concentrate on WTX frameshift mutations only in MSI-H CRCs. Second, these cases were analyzed for mutations in the $B R A F$ - and KRAS- proto-oncogenes (Table 1) applying pyro-sequencing. We found two out of 40 evaluable cases (5\%) with activating mutations in KRAS codons 12 and 13 and 12 out of 39 cases (30.8\%) with an activating mutation in codon 600 of the $B R A F$ gene (p.V600E). Third, WTX frameshift mutations were found in 2 out of the 41 investigated MSI-H CRCs (4.9\%) as shown by FCE and resulted in a $\mathrm{T}_{5}$-repeat (Figure $1 \mathrm{~B}$, tumor ID \#1, \#2), while no such mutations were present in MSS CRCs (Figure 1B, ID \#42). These findings were further confirmed by subcloning the truncated WTX PCR products and subsequent didesoxy-sequencing. Both approaches also revealed signals from the wild type $T_{6}$ repeat in both cases (not shown for direct sequencing), which probably stem from contaminations with normal tissue, as well as signals derived from the second, intact $\mathrm{X}$-chromosome, the latter of course only in case of female patients. The detected frameshift leads to a stop codon (TGA) at position 621 of the coding sequence of the $W T X$-gene, which is of 3.408 bp in length (GenBank: NM_152424). When expressed, such mutated WTX alleles will inevitably result in a truncated protein of 207 instead of wild typic 1.135 amino acids. Such a protein will have no functional properties with respect to the degradation of $\beta$-CATENIN, since the APC and 


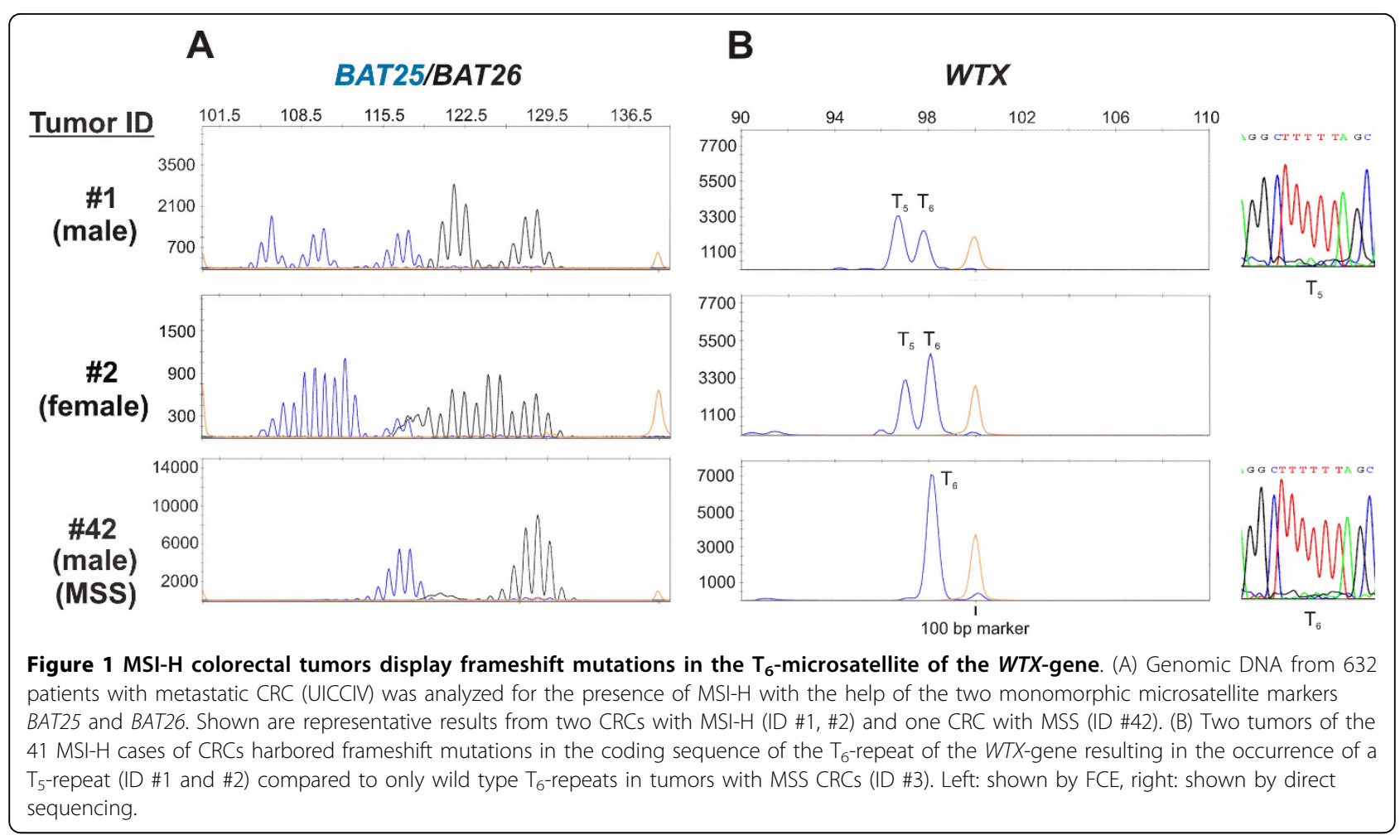

$\beta$-CATENIN interaction domains are located C-terminally of amino acid 207, namely positions 307-789 and in the C-terminus, respectively $[12,13]$. Tumor ID \#2 was additionally characterized by a mutation in the $B R A F$ gene (Table 1). Fourth, we wanted to increase the evidence that the WTX mutations might have a functional relevance for the stabilization of $\beta$-CATENIN in the context of the other members of the WNT signaling pathway $A P C, A X I N 2$ and $C T N N B 1$, which have been described to be mutated in MSI-H CRCs. Therefore, we investigated the described mutational hot spot regions of these three genes in the 41 MSI-H CRCs $[7,8,16,17]$ by direct didesoxy-sequencing (Table 1). Mutations in the APC gene were detected in 6 out of 38 evaluable cases $(15.8 \%)$, in the AXIN2-gene in 7 of $38(18.4 \%)$ and in the CTNNBIgene in 2 of $38(5.3 \%)$ cases. As far as to our knowledge, some of the detected mutations have not been described previously and thus their functional consequences remain to be determined. Importantly, however, we could not find any additional mutations in the two tumors displaying the $W T X \mathrm{~T}_{5}$ frameshift. Fifth, we analyzed the expression of WTX mRNAs in the tumors of the patients with WTX frameshift mutations in order to assess whether these might be of functional relevance for the stabilization of $\beta$-CATENIN. Due to the clonal origin of cancers and the fact that only one X-chromosome is transcriptionally active in women whereas men carry only a single $\mathrm{X}$-chromosome, mutations in X-chromosomal encoded genes like the $W T X$-gene will have a direct functional consequence known as haplo-insufficiency when being expressed. Thus, we checked, first of all, if WTX is commonly expressed in CRCs and especially in the patients carrying $\mathrm{T}_{5}$-repeats in their WTX-genes. The tumors of both patients expressed WTX mRNA (Figure 2A, tumor ID \#1 and \#2), as did MSI-H tumors from patients with wild type WTX genes (Additional file 2, Figure S1 A patient ID \#4 - \#6) or tumors from MSS CRCs (Figure 2A, tumor ID \#42 and Additional file 2, Figure S1 A, tumor ID \#43 and \#44), as well as a panel of cultivated colorectal tumor cell lines (Additional file 2, Figure S1 B). Next, we investigated the length of the $\mathrm{T}_{6}{ }^{-}$microsatellite in the WTX-mRNA. We found that only one of the two tumors (ID \#1, a male patient) harbored the $T_{5}$-frameshift mutation on the transcript level (Figure 2B, tumor ID \#1) and thus inevitably also on the protein level. However, this latter fact could not be verified immunohistochemically due to lack of specific antibodies distinguishing between wild type and mutated WTX protein. The $\mathrm{T}_{5}$-repeat containing tumor of the female patient (ID \#2) expressed wild-type WTX-mRNA, indicating that the mutated gene was located on the inactivated $\mathrm{X}$-chromosome.

\section{Discussion}

MSI-H CRCs constitute approximately $15 \%$ of all CRCs [3] and are generally considered to be 


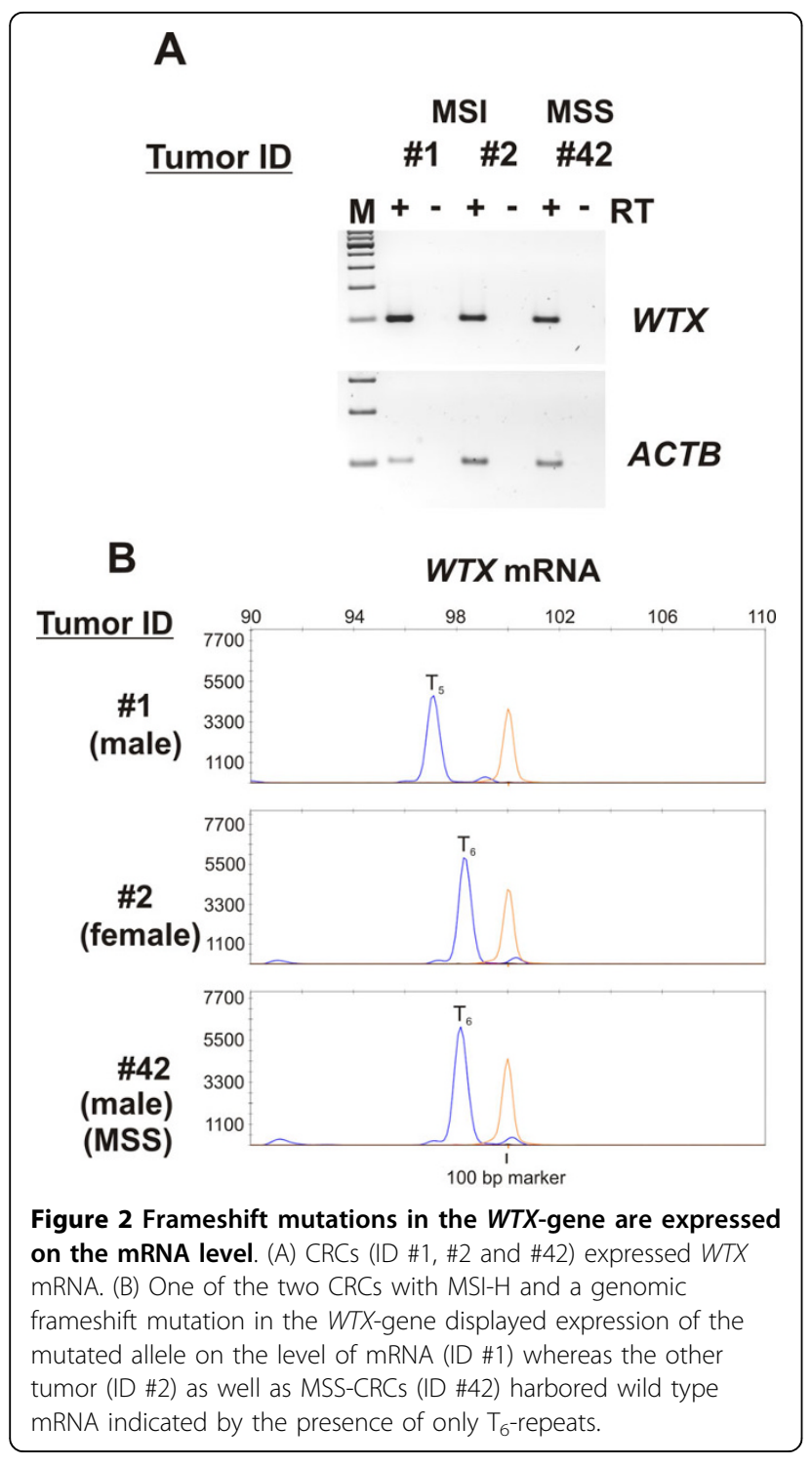

characterized by a better prognosis than tumors of the MSS type [5]. This is reflected by the fact that only $7.9 \%$ of all MSI-H CRCs show progression to a metastatic state (UICCIV), while $27.9 \%$ of MSS cases succeed in forming distant metastases [22]. Thus, the proportion of MSI-H CRCs among tumors in UICCIV has been found to be less compared with the mean value of $15 \%$ in all stages (UICCI - UICCIV) [23] which is in support with $41 \mathrm{MSI}-\mathrm{H}$ cases found in 632 UICCIV cases of CRCs (6.5\%). These results were obtained using the two mononucleotide markers BAT25 and BAT26 instead of the five marker set recommended by the Bethesda guidelines from the National Cancer Institute [20] because these two markers were shown to be of almost the same diagnostic value as all five NCI markers in combination [21]. Furthermore, due to their monomorphic character, usage of BAT25 and BAT26 makes a comparison of normal tissue dispensable.

The difference in clinical behavior of colorectal MSI-H and MSS tumors is also reflected by differences in the mechanisms of genetic instability. MSS CRCs usually mutate the $A P C$ tumor suppressor gene by gross deletions in the genome known as loss of heterozygosity $(\mathrm{LOH})$ or point mutations [24]. As this occurs as the entry mutation in the process of colorectal carcinogenesis $A P C$ is here known as the gatekeeper [1]. In contrast, MSI-H CRCs seem to evolve via a different pathway as mutations in the BRAF or less often KRAS proto-oncogene occur early [3]. Our findings show that in UICCIV less tumors carry BRAF gene mutations ( $28 \%$ compared with up to $75 \%$ in MSI-H tumors of all stages [2]) indicating that in MSI-H tumors BRAF mutations might be somehow protective for progression into UICCIV. Alternatively, the amount of heritable HNPCC tumors might be higher in our collection which do not show mutations in the $B R A F$ gene [2]. Due to changes in the cellular methylation system in sporadic MSI-H tumors the expression of several tumor suppressor genes is turned off due to methylation of its promoter/ exon1. This also seems to be the cause for the loss of the expression of the MLH1 (MUT-L homologue) gene. As a consequence, instability of microsatellites occurs which affects in a second wave of mutations components of the WNT-signaling pathway, like the $A P C$-, or the AXIN2-gene and, as shown here in a small group of cases, additionally in the $W T X$-gene. Since we concentrated on defects leading to the stabilization of $\beta$ CATENIN in MSI-H CRCs, a collection of UICCIV tumors was used because it was expected that later states should contain most if not all mutations leading to the stabilization of $\beta$-CATENIN. One study analyzed in a group of $45 \mathrm{MSI}-\mathrm{H}$ CRCs the occurrence of mutations in the three genes encoding AXIN2 (11/45 24.4\%), APC (4/28 - 14.3\%) and CTNNBI (5/45 - 11.1\%) [8], thus assigning approximately $50 \%$ of MSI-H CRCs with defects in components of the WNT signaling pathway. Assuming that mutations in the WNT-signaling pathway might also be important in MSI-H tumors, it suggests that additional mechanisms might contribute to the stabilization of $\beta$-CATENIN in this tumor entity. The situation turns out to be even more complex as heritable and sporadic forms of tumors display partly great differences in their mutational spectrum as e.g. shown for the CTNNB1 gene where sporadic tumors do not display mutation [11] compared to $43 \%$ in heritable HNPCC cases [10]. Analyzing our mixed collection of UICCIV MSI-H CRCs, we found 15 out 38 evaluable cases $(39.5 \%)$ with mutations in the established components of the WNT signaling pathway. Alternatively, this might be a stage specific effect as it was shown that 
MSI-H tumors are found less frequently in the UICCIV group than MSS tumors which is not the case in the other stages (UICCI - UICCIII) thus indicating a special biology of MSI-H tumors in UICCIV [22]. Here, we add frameshift mutations in the recently identified WTXgene, a component of the $\beta$-CATENIN degradation complex [13], as an additional mechanism which were found at a frequency of $2 / 41$ among MSI-H cases (4.9\%). This frameshift occurred in a 6 thymidine repeat that is located in the $\mathrm{N}$-terminal coding region giving rise to an unfunctional gene product when being transcribed as shown here and translated due to the absence of the APC- and $\beta$-CATENIN interaction domains $[12,13]$. Moreover, we detected several monorepeats of five basepairs in length distributed over the WTX open reading frame which we did not investigate for instability because they are to small to be targets for microsatellite frameshifts [25].

In general a rate of two out of 41 is very low but it is misleading to conclude from mutation rates on the importance of genes as even intronic regions display mutation rates of $54.2 \%$ which are known to be only passenger mutations [26]. Moreover, even high mutation frequencies of $39 \%$ in the TCF4 gene (T-cell transcription factor 4) [27] which has an important role in WNT-signaling are not warranting that the mutations might have a physiologic effect [28]. Thus, the finding that 1 patient (2.5\%) expressed the genetic alteration on the mRNA level may be an indicator that alterations in the WTXgene might have a functional role for the stabilization of $\beta$-CATENIN and have in this case the status of a driver mutation. This accounts especially in the context of absent other mutations in the WNT pathway (Table 1) and when considering that this patient with tumor ID \#1 was a 65 years old man with probably a sporadic tumor and that WTX is located on the X-chromosome. Moreover, our mutation frequency is consistent with another study, which detected only a single mutation in 47 CRCs $(2.1 \%)$, irrespective of the MSI status [29]. While the functional consequene of this described point mutation is unknown, this and our work at least indicate that mutations in WTX might be involved in colorectal carcinogenesis in a small proportion of both, MSI-H as well as MSS tumors. Interestingly, our result that the tumor of a female patient displayed the mutation in the $W T X$-gene on the transcriptionally inactive X-chromosome is in support with findings from Wilms tumors where mutations of the WTX-gene were also found on the inactivated $\mathrm{X}$-chromosome in women [14]. Obviously, larger cohorts are needed for definitively answering the open questions about the frequency of WTX-gene mutations and the prevalence of mutations on the inactivated $X$ chromosome in female patients.

\section{Conclusion}

Taking together, we demonstrate that mutations in the WTX-gene might play a role in the process of MSI-H colorectal carcinogenesis in a small subgroup of these tumors as has been modeled for Wilms Tumors before [30]. This implies that WTX-gene mutations should be reconsidered in future studies dealing with MSI-H CRCs, especially in the context of the other known mutations leading to stabilization of $\beta$-CATENIN. Importantly, a functional role of these mutations for the process of colorectal carcinogenesis has to be investigated in further works in the future.

\section{Additional material}

Additional file 1: Table S1 Oligonucleotides used in this study.

Additional file 2: Figure S1 CRCs as well as colorectal tumor cell lines express WTX mRNA. (A) All cases of CRCs tested expressed WTX mRNA irrespective of being MSI-H (ID \#1, \#2 and \#4 to \#6) or MSS (ID \#42 to \#44). (B) A panel of cultivated CRC cell lines also expressed WTX mRNA. PCR specific for the housekeeping gene ACTB ( $\beta$-ACTIN) served as a control.

\section{Acknowledgements}

We thank Jutta Hügel-Tegge, Gabi Charell, Margit Mattei, and Nicole Perera for their help in preparing and providing genomic DNA for the cases under investigation. This work was supported by the Wilhelm-Sander Stiftung, Germany (grant No 2004-111.2, to AJ and TK).

\section{Author details}

${ }^{1}$ Pathologisches Institut der Ludwig-Maximilians-Universität München, Thalkirchner Straße 36, 80337 Munich, Germany. ${ }^{2}$ Universitätsklinik und Poliklinik für Innere Medizin I, Medizinische Fakultät der Martin-Luther Universität Halle-Wittenberg, Ernst-Grube Straße 40, 06097 Halle, Germany.

\section{Authors' contributions}

SKS coordinated the study, designed and partly optimized the analytical tools. He generated and analyzed the data. Moreover, he wrote the draft of the manuscript. SP generated and analyzed data in part, MP developed and optimized part of the mutation detection system of the APC gene as part of his MD work, SO was involved in the initial planning of the study, TK approved the study and AJ designed and coordinated the study. He was involved in the analysis of the data and brought the manuscript into its final form. All authors read and approved to the final form of the manuscript.

Author's information

This project is part of the PhD thesis of SKS.

Competing interests

The authors declare that they have no competing interests.

Received: 22 December 2009 Accepted: 9 August 2010

Published: 9 August 2010

\section{References}

1. Kinzler KW, Vogelstein B: Lessons from hereditary colorectal cancer. Cell 1996, 87:159-170.

2. Weisenberger DJ, Siegmund KD, Campan M, Young J, Long TI, Faasse MA, Kang GH, Widschwendter M, Weener D, Buchanan D, et al: CpG island methylator phenotype underlies sporadic microsatellite instability and is tightly associated with BRAF mutation in colorectal cancer. Nat Genet 2006, 38:787-793. 
3. Ogino S, Goel A: Molecular classification and correlates in colorectal cancer. J Mol Diagn 2008, 10:13-27.

4. Markowitz S, Wang J, Myeroff L, Parsons R, Sun L, Lutterbaugh J, Fan RS, Zborowska $\mathrm{E}$, Kinzler KW, Vogelstein B, et al: Inactivation of the type II TGF-beta receptor in colon cancer cells with microsatellite instability. Science 1995, 268:1336-1338.

5. Popat S, Hubner R, Houlston RS: Systematic review of microsatellite instability and colorectal cancer prognosis. J Clin Oncol 2005, 23:609-618.

6. Shitoh K, Furukawa T, Kojima M, Konishi F, Miyaki M, Tsukamoto T, Nagai H: Frequent activation of the beta-catenin-Tcf signaling pathway in nonfamilial colorectal carcinomas with microsatellite instability. Genes Chromosomes Cancer 2001, 30:32-37.

7. Huang J, Papadopoulos N, McKinley AJ, Farrington SM, Curtis LJ, Wyllie AH, Zheng S, Willson JK, Markowitz SD, Morin P, et al: APC mutations in colorectal tumors with mismatch repair deficiency. Proc Natl Acad Sci USA 1996, 93:9049-9054.

8. Liu W, Dong X, Mai M, Seelan RS, Taniguchi K, Krishnadath KK, Halling KC, Cunningham JM, Boardman LA, Qian C, et al: Mutations in AXIN2 cause colorectal cancer with defective mismatch repair by activating betacatenin/TCF signalling. Nat Genet 2000, 26:146-147.

9. Polakis P: Wnt signaling and cancer. Genes Dev 2000, 14:1837-1851.

10. Miyaki M, lijima T, Kimura J, Yasuno M, Mori T, Hayashi Y, Koike M, Shitara N, Iwama T, Kuroki T: Frequent mutation of beta-catenin and APC genes in primary colorectal tumors from patients with hereditary nonpolyposis colorectal cancer. Cancer Res 1999, 59:4506-4509.

11. Salahshor S, Kressner U, Pahlman L, Glimelius B, Lindmark G, Lindblom A: Colorectal cancer with and without microsatellite instability involves different genes. Genes Chromosomes Cancer 1999, 26:247-252.

12. Grohmann A, Tanneberger K, Alzner A, Schneikert J, Behrens J: AMER1 regulates the distribution of the tumor suppressor APC between microtubules and the plasma membrane. J Cell Sci 2007, 120:3738-3747.

13. Major MB, Camp ND, Berndt JD, Yi X, Goldenberg SJ, Hubbert C, Biechele TL, Gingras AC, Zheng N, Maccoss MJ, et al: Wilms tumor suppressor WTX negatively regulates WNT/beta-catenin signaling. Science 2007, 316:1043-1046.

14. Perotti D, Gamba B, Sardella M, Spreafico F, Terenziani M, Collini P, Pession A, Nantron M, Fossati-Bellani F, Radice P: Functional inactivation of the WTX gene is not a frequent event in Wilms' tumors. Oncogene 2008, 27:4625-4632.

15. Rivera MN, Kim WJ, Wells J, Driscoll DR, Brannigan BW, Han M, Kim JC, Feinberg AP, Gerald WL, Vargas SO, et al: An X chromosome gene, WTX, is commonly inactivated in Wilms tumor. Science 2007, 315:642-645.

16. Mirabelli-Primdahl L, Gryfe R, Kim H, Millar A, Luceri C, Dale D, Holowaty E, Bapat B, Gallinger S, Redston M: Beta-catenin mutations are specific for colorectal carcinomas with microsatellite instability but occur in endometrial carcinomas irrespective of mutator pathway. Cancer Res 1999, 59:3346-3351.

17. Morin PJ, Sparks AB, Korinek V, Barker N, Clevers H, Vogelstein B, Kinzler KW: Activation of beta-catenin-Tcf signaling in colon cancer by mutations in beta-catenin or APC. Science 1997, 275:1787-1790.

18. Ogino S, Kawasaki T, Brahmandam M, Yan L, Cantor M, Namgyal C, MinoKenudson M, Lauwers GY, Loda M, Fuchs CS: Sensitive sequencing method for KRAS mutation detection by Pyrosequencing. J Mol Diagn 2005, 7:413-421.

19. Poehlmann A, Kuester D, Meyer F, Lippert H, Roessner A, Schneider-Stock R: K-ras mutation detection in colorectal cancer using the Pyrosequencing technique. Pathol Res Pract 2007, 203:489-497.

20. Boland CR, Thibodeau SN, Hamilton SR, Sidransky D, Eshleman JR, Burt RW, Meltzer SJ, Rodriguez-Bigas MA, Fodde R, Ranzani GN, Srivastava S: A National Cancer Institute Workshop on Microsatellite Instability for cancer detection and familial predisposition: development of international criteria for the determination of microsatellite instability in colorectal cancer. Cancer Res 1998, 58:5248-5257.

21. Deschoolmeester V, Baay M, Wuyts W, Van Marck E, Van Damme N, Vermeulen P, Lukaszuk K, Lardon F, Vermorken JB: Detection of microsatellite instability in colorectal cancer using an alternative multiplex assay of quasi-monomorphic mononucleotide markers. $J \mathrm{Mol}$ Diagn 2008, 10:154-159.

22. Malesci A, Laghi L, Bianchi P, Delconte G, Randolph A, Torri V, Carnaghi C, Doci R, Rosati R, Montorsi M, et al: Reduced likelihood of metastases in patients with microsatellite-unstable colorectal cancer. Clin Cancer Res 2007, 13:3831-3839.

23. Fallik D, Borrini F, Boige V, Viguier J, Jacob S, Miquel C, Sabourin JC, Ducreux M, Praz F: Microsatellite instability is a predictive factor of the tumor response to irinotecan in patients with advanced colorectal cancer. Cancer Res 2003, 63:5738-5744.

24. Albuquerque $C$, Breukel $C$, van der Luijt R, Fidalgo P, Lage P, Slors FJ, Leitao CN, Fodde R, Smits R: The 'just-right' signaling model: APC somatic mutations are selected based on a specific level of activation of the beta-catenin signaling cascade. Hum Mol Genet 2002, 11:1549-1560.

25. Woerner SM, Benner A, Sutter C, Schiller M, Yuan YP, Keller G, Bork P, Doeberitz MK, Gebert JF: Pathogenesis of DNA repair-deficient cancers: a statistical meta-analysis of putative Real Common Target genes. Oncogene 2003, 22:2226-2235.

26. Zhang L, Yu J, Willson JK, Markowitz SD, Kinzler KW, Vogelstein B: Short mononucleotide repeat sequence variability in mismatch repair-deficient cancers. Cancer Res 2001, 61:3801-3805.

27. Duval A, Gayet J, Zhou XP, lacopetta B, Thomas G, Hamelin R: Frequent frameshift mutations of the TCF-4 gene in colorectal cancers with microsatellite instability. Cancer Res 1999, 59:4213-4215.

28. Ruckert S, Hiendlmeyer E, Brueckl WM, Oswald U, Beyser K, Dietmaier W, Haynl A, Koch C, Ruschoff J, Brabletz T, et al: T-cell factor-4 frameshift mutations occur frequently in human microsatellite instability-high colorectal carcinomas but do not contribute to carcinogenesis. Cancer Res 2002, 62:3009-3013.

29. Yoo NJ, Kim S, Lee SH: Mutational analysis of WTX gene in Wnt/betacatenin pathway in gastric, colorectal, and hepatocellular carcinomas. Dig Dis Sci 2009, 54:1011-1014.

30. Nusse R: Cancer. Converging on beta-catenin in Wilms tumor. Science 2007, 316:988-989.

\section{Pre-publication history}

The pre-publication history for this paper can be accessed here:

http://www.biomedcentral.com/1471-2407/10/413/prepub

\section{doi:10.1186/1471-2407-10-413}

Cite this article as: Scheel et al.: Mutations in the WTX - gene are found in some high-grade microsatellite instable (MSI-H) colorectal cancers. BMC Cancer 2010 10:413.

\section{Submit your next manuscript to BioMed Central and take full advantage of:}

- Convenient online submission

- Thorough peer review

- No space constraints or color figure charges

- Immediate publication on acceptance

- Inclusion in PubMed, CAS, Scopus and Google Scholar

- Research which is freely available for redistribution

Submit your manuscript at www.biomedcentral.com/submit
C) Biomed Central 